Педагогика и психология образования. 2020. № 3

DOI: 10.31862/2500-297X-2020-3-173-191

\title{
С.Б. Шубин
}

Школа № 460 имени дважды Героев Советского Союза

А.А. Головачёва и С.Ф. Шутова, 109387 г. Москва, Российская Федерация

\section{Психологические особенности цифровой активности подростКов на примере социальных сетей: обзор иностранных исследований}

В статье дан обзор современных зарубежных исследований, описывающих психологические особенности поведения подростков в социальных сетях. Автору в результате проделанной аналитической работы удалось выявить ряд положительных и отрицательных сторон использования подростками социальных сетей. К положительным сторонам можно отнести возможность получения социальной поддержки и упрощение процесса межличностной коммуникации. Среди отрицательных - проявления травли подростками друг друга («кибербуллинг»), распространение и употребление психоактивных веществ и пр. Проведен обзор «Бергенской шкалы зависимости от социальных сетей» (BSMAS), даны переведенные на русский язык бланк и ключ теста.

Ключевые слова: подростки в социальных сетях, влияние социальных сетей, травля в социальных сетях, кибербуллинг, проблемное использование социальных сетей, социально-психологическая поддержка, депрессивное расстройство и социальные сети

ССЫЛКА НА СТАТЬЮ: Шубин С.Б. Психологические особенности цифровой активности подростков на примере социальных сетей: обзор иностранных исследований // Педагогика и психология образования. 2020. № 3. С. 173-191. DOI: $10.31862 / 2500-297 X-2020-3-173-191$ 
DOI: 10.31862/2500-297X-2020-3-173-191

\section{S. Shubin}

State Budgetary Educational Institution "School No. 460", Moscow, 109387, Russian Federation

\section{Psychological features of adolescent digital activity on the example of social networks: the review of foreign studies}

The article gives a review of new foreign studies describing the psychological characteristics of adolescent behavior in social networks. As a result of the analysis, it was possible to identify a number of positive and negative aspects of the use of social networks by adolescents. The positive aspects include the possibility of obtaining social support through social networks, and the simplification of the process of interpersonal communication. The negative aspects include manifestations of bullying by teenagers in relation to each other on social networks ("cyberbullying"), as well as the spread and use of psychoactive substances by teenagers using social networks, etc. A review of the "Bergen Social Media Addiction Scale" (BSMAS) was conducted. Translated into Russian forms and test key are presented.

Key words: adolescents in social networks, influence of social networks, social network bullying, cyberbullying, problematic social networking site use, depressive disorder and social networks, socio-psychological support

CITATION: Shubin S.B. Psychological features of adolescent digital activity on the example of social networks: The review of foreign studies. Pedagogy and Psychology of Education. 2020. No. 3. Pp. 173-191. (In Russ.). DOI: 10.31862/2500297X-2020-3-173-191

\section{Введение}

В последние годы социальные сети стали неотъемлемой частью жизни. Отдельное место они занимают в структуре жизненного пространства подростков. По данным ВЦИОМ [1], значительное число подростков 
проводят в социальных сетях и видеоиграх 7 и более часов в день, затраты времени непосредственно на социальные сети согласно данным Ф. Банья, М.Д. Гриффитс и др., составляют до 4-5 часов в день [7; 8]. Как показывают исследования С.К. Рыженко, Н.В. Омельченко, Н.В. Богачевой, Н.А. Добровидовой, М.И. Дрепы, О.В. Завалишиной, И.В. Колотиловой и др., в среднем на видеоигры подростки тратят от 2 до 3 часов в день. Доступ к социальным сетям при помощи смартфона легче, чем к качественным видеоиграм, которые требуют наличия мощного, дорогого, часто стационарного домашнего компьютера или игровой приставки. Данный фактор может определять повышенные показатели временных затрат среди подростков на социальные сети, по сравнению с затратами времени на видеоигры. По данным ВЦИОМ, 89\% опрошенных школьников пользуются социальными сетями почти каждый день [1]. Подобный образ жизни современных школьников заставляет психологическую науку обратить внимание на особенности их поведения в виртуальном мире. Важно понять, какие причины приводят подростка в социальную сеть и стимулируют находиться в ней не менее половины светового дня, наносит ли это вред подростку, или наоборот является нормой или даже приносит пользу.

В российском научном поле известно большое число авторов (К.А. Демичева, А.С. Дужникова, А.Е. Войскунский, В.С. Собкин и А.В. Федотова, Ю.В. Судич, П.А. Ломакин, В.И. Новосельцев, Д.И. Семенов, Р.А. Внебрачных, В.С. Тоискин и др.), включивших психологические особенности использования подростками социальных сетей в сферу своего научного интереса. Однако зарубежный опыт исследований на данную тематику значительно меньше известен российскому читателю, несмотря на то, что первые работы, описывающие влияние виртуального компьютерного пространства на подростков, появились в западных странах в конце 1990-х гг. прошлого века (А.К. Голдберг, К.С. Янг, Д. Гринфилд и др.).

Учитывая сказанное, целью данной статьи является анализ современных зарубежных исследований, описывающих психологические особенности использования подростками социальных сетей, в частности возможные негативные и позитивные последствия такого поведения.

\section{Методы}

Поиск публикаций для целей данного аналитического исследования проводился с использованием базы данных PubMed (www.ncbi. nlm.nih.gov/pubmed) в период с апреля по ноябрь 2019 г. Ключевыми словами, использованными в процессе поиска публикаций, были: 
«проблемное использование социальных сетей», «кибербуллинг», «борьба с кибербуллингом», «влияние социальных сетей», «зависимость от социальных сетей», «интернет-зависимость», «опасность социальных сетей», «социальная сеть в жизни подростка», «польза социальных сетей» и пр. В результате анализа названий и аннотаций было выделено более 100 публикаций.

Далее в соответствии с критериями отбора были выбраны 38 работ. Отбор происходил по следующим критериям. Для аналитических, обзорных статей - рецензируемые работы, опубликованные не позднее 2015 г. с общей численностью рассмотренных публикаций не менее 100. Для статей, включающих эмпирические исследования, рецензируемые работы, опубликованные не позднее 2016 г. с общей численностью выборки не менее 500 респондентов, содержащие преимущественно параметрические статистические методы анализа данных. Отбирались работы, содержащие констатирующие, сравнительные, в том числе лонгитюдные эксперименты. Временной критерий применялся избирательно к статьям, посвященным разработке нового и апробации имеющегося инструментария для оценки влияния социальных сетей на человека.

В рассмотренных эмпирических исследованиях и обзорных аналитических статьях изучаются особенности цифровой активности как нормативных подростков, так и подростков, имеющих различные проблемы психологического характера, а также проблемы социального спектра.

В результате перевода и извлечения данных из отобранных 38 публикаций для более детального анализа были выбраны 13 работ, наиболее полно отвечающих критериям отбора и соответствующих теме аналитического исследования.

\section{Особенности использования социальных сетей в подростковой среде}

Среди факторов негативного влияния социальных сетей на школьников в зарубежном научном поле наиболее часто поднимается проблема травли и издевательств со стороны сверстников. Социальные сети как коммуникативное пространство создают ряд уникальных условий, позволяющих осуществлять травлю и другие насильственные действия практически безнаказанно.

Коллектив авторов из США Ж. Неси, С. Чукас-Брэдли и М.Дж. Принштейн в результате масштабного аналитического исследования изучил, каким образом социальные сети влияют на общение и межличностное взаимодействие в среде современных подростков, не имеющих психологических отклонений, а также подростков, имеющих симптомы 
депрессивного и иных расстройств. Исследователи выделяют несколько уникальных особенностей, имеющих отношение к процессам коммуникации, которые отличают социальные медиа от реального, традиционного общения [30]. Назовем те особенности общения в социальных сетях, которые способны провоцировать травлю и издевательства в сети.

1. Анонимность. Возможность скрывать информацию о себе (выбирать возраст и пол), демонстрировать себя только с хорошей стороны.

2. Постоянство или неизменность. Характеризуется тем, что единожды отправленное текстовое или видео сообщение в социальной сети навсегда остается доступным для повторного прочтения или просмотра в неизменном виде.

3. Отсутствие невербальных сигналов в процессе общения, таких как тон голоса, зрительный контакт (жесты и выражение лица) [30, c. 267-294], способствует обезличиванию и как следствие облегчению инициации агрессии.

В другой своей работе авторы изучили особенности травли в социальных сетях (кибербуллинга). Исследователи сообщают, что среди подростков стала популярна травля сверстников-изгоев путем анонимной рассылки друзьям жертвы порочащей, лживой информации о ней $[9 ; 11$; $20 ; 29 ; 30 ; 32 ; 38 ; 40]$. Другим способом травли является взлом аккаунта жертвы и рассылка различных непристойных сообщений с этого аккаунта другим пользователям [11]. Возможен и такой вид издевательств, при котором один подросток втягивает жертву в спор при помощи социальной сети, но за этим спором наблюдают другие участники травли, которые постепенно встают на сторону нападающего, тем самым превращая спор двух людей в травлю одного подростка сразу несколькими нападающими.

Очевидно, что подобные действия могут нанести вред подростку, для которого социальный статус и чувство собственного достоинства крайне важны. Возможность напоминания жертве об акте агрессии, учитывая наличие постоянного доступа к доказательствам травли в социальной сети, значительно усугубляет ситуацию [31, с. 295-319; 39].

В других исследованиях также отмечаются такие виды кибербуллинга, как исключение из общей группы в социальной сети и последующее обсуждение подростка в негативном ключе $[8 ; 13 ; 29 ; 37 ; 40]$, создание «страницы ненависти», отдельной группы в социальной сети, посвященной оскорблениям и сплетням в отношении жертвы [40]. Отдельного внимания заслуживают издевательства в сети по расовому, религиозному, социальному и половому признакам, а также на сексуальной почве [24; 29]. Анонимность присутствия в социальной сети позволяет нападающим избежать довольно жесткого, часто уголовного наказания. 
Исследователи из Испании Б. Мартинес-Феррер, Д. Морено, Г. Муситу также изучили особенности агрессии и виктимизации среди нормативных подростков в социальных сетях. Авторы провели тестирование 1952 школьников в возрасте от 11 до 16 лет. В результате выяснилось, что часть подростков, наиболее часто использующих социальные сети, демонстрирует повышенный уровень агрессивности, в особенности словестной. Также были продемонстрированы гендерные различия: мальчики чаще, чем девочки, используют все анализируемые измерения агрессии в социальных сетях, за исключением реляционной агрессии (агрессивное поведение, направленное на разрушение вашего места в обществе), где девочки демонстрируют более высокие баллы [25].

Исследования показывают, что подростки, часто использующие социальные сети, практически постоянно сталкиваются с явной словесной в т.ч. реляционной агрессией, происходит их виктимизация [11; 24; 25]. Именно реляционный тип агрессии в социальных сетях оказывает наиболее негативное влияние на школьников. Подростки, подвергаясь нападкам со стороны сверстников, вынуждены сами активно применять агрессивные действия, чтобы не потерять свой социальный статус. В результате создается «порочный круг», в котором агрессия порождает агрессию, однако в отличие от реального мира, где агрессия ограничена физическим присутствием и возможной личной ответственностью, социальная сеть дает возможность обезличенного присутствия и нападения на жертву, что значительно ожесточает взаимную травлю [25, с. 801].

Важно отметить, что проблема кибербуллинга довольно давно изучается за рубежом, в частности в западных странах. Поэтому там накоплен большой опыт удачных вмешательств и рекомендаций, направленных на снижение и профилактику кибербуллнга в школах. Так Дж. Финн, Э. Роланд, Ф. Свартдал предлагают свою модель реляционной реабилитации.

1. Повышение авторитета учителя.

2. Перераспределение социальной власти и содействие дружному классному коллективу. Если в классе царит жестокость и нетерпимость, то власть и авторитет всегда будут принадлежать хулиганам.

3. Обучение подростков нормам социального и эмоционального поведения, активное положительное подкрепление дружелюбного поведения со стороны учителя и на уровне школьной администрации [17]. См. также [14; 18; 29].

В ряде других работ предлагаются такие меры, как создание в школе анонимной онлайн-службы для жертв кибербуллинга [13]; публичное 
оповещение учащихся и учителей о правовых последствиях запугивания в интернете и способах правовой борьбы с этим явлением; информационное просвещение в области кибербуллинга, направленное на преподавательский состав и родителей учащихся [18; 29; 38].

Другой важной проблемой, которой посвящено большое число зарубежных работ, является влияние постоянного использования социальных сетей подростками на возникновение и развитие у них различных сопутствующих психологических расстройств. Авторы из Британии 3. Хуссейн и М.Д. Гриффитс провели анализ 100 исследований на данную тему, опубликованных с 2014 г. [19]. В результате было отобрано девять работ, отвечающих теме аналитического исследования. В шести работах показана корреляция между постоянным использованием социальных сетей подростками и симптомами депрессивного расстройства, в пяти исследованиях с тревожностью [8; 30; 36]. Возможности социальной сети позволяют избежать психотравмирующих ситуаций, которые имеют место в реальном мире, в результате чего подростки, имеющие симптомы депрессивного расстройства, используют социальную сеть для ухода от реальности и проводят в ней большую часть дня. В одном исследовании была показана связь частого использования социальных сетей с ухудшением симптомов дефицита внимания и гиперактивности (СДВГ) [3]. Часто возникающие сообщения и реклама в социальной сети заставляют подростка с СДВГ постоянно заходить в сеть для проверки сообщений и ответов на них.

Кроме того, в двух рассмотренных исследованиях была показана связь между частым использованием социальной сети и стрессом $[5 ; 33]$, в одном исследовании - с обсессивно-компульсивным расстройством [3]. 3. Хуссейн и М.Д. Гриффитс утверждают, что установить прямую взаимосвязь между возникновением психологического расстройства и частым использованием социальных сетей в большинстве исследований не представляется возможным. Однако доказательства того, что подростки, имеющие те или иные психологические проблемы, тратят на социальные сети значительно больше времени, чем их сверстники, не имеющие психологических проблем, выглядят вполне надежными $[19$, с. 686].

Выводы британских авторов подтверждаются исследованием, проведенным в Китае [23]. В процессе проведения эксперимента тестирование на предмет наличия симптомов депрессии прошли 5365 учеников средней школы (Гуанчжоу, Южный Китай), также подростков опросили на тему того, как часто они используют социальные сети. Спустя девять месяцев авторы повторили процедуру эксперимента с теми же 
школьниками и выяснили, что 48\% подростков, имевших симптомы депрессии, но использующих социальные сети умерено в начале исследования, по истечении девяти месяцев продемонстрировали значительное увеличение затрат времени на социальные сети. Интересно, что при повторном тестировании подростки, у которых выявили симптомы депрессии впервые, не сообщали о наличии больших временных затратах на пользование социальными сетями [23].

Подобные данные позволили китайским исследователям сделать вывод о том, что депрессивное расстройство может являться катализатором в процессе увеличения активности подростков в социальных сетях, что подтверждают другие авторы $[8 ; 11 ; 36]$. По мнению исследователей, психологические программы профилактики повышения активности подростков в социальных сетях должны в первую очередь выявлять и корректировать имеющиеся у школьников первичные психологические расстройства, в т.ч. депрессивного характера $[11 ; 23$, c. 686-696].

Отметим работу исследователей из Норвегии Г.С. Брунборг и А.Дж. Бурджович, которые провели практически идентичный китайским коллегам лонгитюдный эксперимент на выборке в 769 подростков. Авторы получили схожие результаты, однако среди основных причин повышения затрат времени на пользование социальными сетями, наряду с проявлением симптомов депрессивного расстройства, исследователи выделяют проблемы социального характера в реальной жизни подростков, от которых те пытаются укрыться в сети [12, с. 201-209].

Еще одной проблемой в фокусе внимания зарубежного научного сообщества является роль социальных сетей в процессе распространения различных психоактивных веществ (ПАВ). Коллектив исследователей из Италии К. Милиано, Дж. Марджани и др. изучил деятельность анонимных групп в социальных сетях, занимающихся распространением запрещенных ПАВ [27].

Многие исследования указывают на то, что в наиболее крупных социальных сетях Facebook или Twitter существуют группы и приложения, рекламирующие лекарства, благовония, соли для ванн, биодобавки и пр. При более детальном анализе таких групп оказалось, что на самом деле они открыто, на законных основаниях, продают ПАВ за счет наличия временного промежутка с момента появления нового вещества на рынке до его внесения в список регулируемых веществ $[16 ; 28 ; 34 ; 41]$.

Особенной популярностью у подростков пользуются модифицированные разными добавками вещества для «вейпа» (курение при 
помощи процесса пароиспарения). Кроме того, существуют отдельные сайты (например, www.drugs-forum.com и www.erowid.org), на которых молодые люди делятся своим опыт употребления ПАВ. Посещение таких сайтов не требует идентификации и доступно, в том числе для несовершеннолетних. Отдельного внимания заслуживают каналы на социальном видеохостинге YouTube, набравшие значительную аудиторию за счет демонстрации процесса воздействия того или иного ПАВ на человека [34]. Отсутствие эффективного контроля на данный момент не позволяет ограничить работу подобных сайтов и групп в социальных сетях [27, с. 152-160]. Данная проблема актуальна и для России, но, кроме курительных смесей для «вейпа», в среде российских подростков распространено употреблению «снюса» (жевательного табака), который также часто содержит дополнительные психоактивные добавки и свободно продается в интернете.

Важными видятся данные, полученные специалистами из США С.Ю. Ким, Л.А. Марш и др. В своем исследовании авторы показали, что помимо продажи наркотических средств, в социальных сетях распространена нерецептурная продажа официально разрешенных медицинских психоактивных препаратов $[16 ; 21 ; 28]$.

В некоторых случаях в среде подростков, постоянно использующих социальные сети, травля и издевательства, сопутствующие психические расстройства и проблемы с наркотическими веществами приводят к попыткам нанесения себе вреда и даже к суицидальным наклонностям. Коллектив авторов из США А.М. Мемон, Ш.Г. Шарма, С. Сатьяджит и Дж. Шайлеш, провели систематический обзор имеющихся исследований на данную тему [26].

В результате анализа отобранных работ авторы выяснили, что существуют отдельные сайты (www.suicideforum.net), и группы в социальных сетях, где подростки, имевшие опыт нанесения себе вреда, общаются друг с другом, часто инкогнито, для получения социальной поддержки и обсуждения подробностей своего поступка. Часто в подобные группы вступают подростки, которые не имели опыта нанесения себе вреда, но собираются это сделать. Некоторые пользователи таких групп получают положительные и поддерживающие сообщения, в то время как другие сталкиваются с негативными советами, направленными на провокацию суицидальных действий. Другим важным фактором, провоцирующим мысли о суициде, являются видео в социальных сетях и на видеохостингах, таких как YouTube, на которых запечатлены кадры нанесения себе вреда $[10 ; 31]$. Авторы сообщают, что подобные видео набирают большое число просмотров, в том числе среди 
несовершеннолетних. Отдельного внимания заслуживают сайты и группы в социальных сетях, пропагандирующие худобу, часто на таких ресурсах здоровые подростки общаются с подростками, страдающими анорексией, восхищаются их худобой и стараются им подражать.

Подводя итоги, исследователи делают вывод о том, что наибольшему риску нанесения себе вреда и совершению суицида подвержены подростки, имеющие те или иные психические расстройства, как правило, депрессивного характера [26]. Также в группе риска находятся школьники, которые подвергаются систематической травле через социальные сети $[2 ; 20 ; 32]$, и школьники, имеющие социальные проблемы, мешающие их успешной адаптации в обществе. Социальные сети в этом ключе являются для подростков удобным и безопасным инструментом для получения и обсуждения специфической информации о суициде [10; 26, с. 384-392], а также способом публичной демонстрации процесса и последствий нанесения себе вреда.

Во многих рассмотренных нами исследованиях авторы говорят о так называемом «Проблемном использовании интернета / социальных сетей» подростками, которое часто выявляется путем тестирования школьников при помощи популярной на западе и в других регионах мира Бергенской шкалы зависимости от социальных сетей (Bergen Social Media Addiction Scale BSMAS) $[3 ; 4 ; 7 ; 8 ; 11 ; 19 ; 24 ; 25 ; 35 ; 36]$. Одно из первых упоминаний данного теста состоялось в 2012 г. в работе сотрудников факультета психологических наук Университета Бергена (Норвегия) С.С. Андреассен, Т. Торбьерн и др. [4, с. 505]. В 2012 г. данный тест включал 18 вопросов и был направлен исключительно на изучение особенностей использования социальной сети Facebook [4, с. 516].

На данный момент экспресс-тест прошел модификацию и состоит из 6 вопросов, оценивающих особенности использования любой социальной сети респондентом за последний год. Респондент дает ответ в соответствии с 5-балльной шкалой Лайкерта (все ответы оцениваются в баллах: 1 - очень редко, 2 - редко, 3 - иногда, 4 - часто, 5 - очень часто) [3, с. 261] (табл. 1).

Исследования при помощи BSMAS и процедура валидизации теста проходили во многих странах Европы, Азии и Северной Америки. Показательным примером может служить исследование, проведенное венгерскими учеными, которые попытались дать характеристику «Проблемному использованию социальных сетей». Выборка исследования была составлена из подростков, обучающихся в 9-10 классах венгерских общеобразовательных школ, в количестве 5961 человек. Школьники 


\section{Бергенская шкала зависимости от социальных сетей}

\section{(Bergen Social Media Addiction Scale [3]. Перевод автора статьи)}

Инструкиия. Ниже Вы найдете несколько вопросов о Вашем отношении к социальным сетям и об особенностях использования Вами социальных сетей (Facebook, Twitter, Instagram и др.). Выберете вариант ответа для каждого вопроса, который лучше всего Вам подходит.

\begin{tabular}{|l|l|l|l|l|l|}
\hline \multicolumn{1}{|c|}{ Как часто за последний год Вы... } & $\begin{array}{l}\text { Очень } \\
\text { редко }\end{array}$ & Редко & Иногда & Часто & $\begin{array}{c}\text { Очень } \\
\text { часто }\end{array}$ \\
\hline $\begin{array}{l}\text { № 1. ...тратили много времени, } \\
\text { думая о социальных сетях или } \\
\text { планируя (предвкушая) исполь- } \\
\text { зование социальных сетей? }\end{array}$ & & & & & \\
\hline $\begin{array}{l}\text { № 2. ... ощущали желание } \\
\text { использовать социальные сети } \\
\text { все больше и больше? }\end{array}$ & & & & & \\
\hline $\begin{array}{l}\text { № 3. ...использовали социаль- } \\
\text { ные сети, чтобы забыть (отвлечь- } \\
\text { ся) о личных проблемах? }\end{array}$ & & & & & \\
\hline $\begin{array}{l}\text { № 4. ...пытались сократить } \\
\text { затраты времени на исполь- } \\
\text { зование социальных сетей, } \\
\text { но не достигли успеха? }\end{array}$ & & & & & \\
\hline $\begin{array}{l}\text { № 5. ...становились обеспокое- } \\
\text { ны или раздражительны в усло- } \\
\text { виях, когда Вам было запрещено } \\
\text { использовать социальные сети? }\end{array}$ & & & & & \\
\hline $\begin{array}{l}\text { № 6. ...использовали социаль- } \\
\text { ные сети настолько много, что } \\
\text { это отрицательно сказалось } \\
\text { на Вашей работе/учебе? }\end{array}$ & & & & & \\
\hline
\end{tabular}

Примечание. Компоненты зависимости (Шкалы): 1 - значимость (озабоченность поведением); 2 - толерантность (увеличение частоты и увлеченности использования социальных сетей с течением времени, для достижения первоначальных эффектов изменяющих настроение / дающих положительные эмоции); 3 - изменение настроения (поведение, направленное на облегчение неприятных эмоциональных состояний); 4 - рецидив / потеря контроля (безуспешная попытка сократить или контролировать использование социальных сетей); 5 - абстиненция (появление психологического и физического дискомфорта, когда доступ к социальным сетям снижен или недоступен); 6 конфликт / проявление дезадаптации (откладывание или пренебрежение социальными, развлекательными, рабочими, образовательными, бытовыми и/или другими видами деятельности, а также своими и чужими потребностями из-за постоянного пользования социальной сетью.

Номер каждой шкалы соответствует номеру вопроса. 
также прошли тестирование с целью определения уровня самооценки и выраженности симптомов депрессивного расстройства. В результате анализа полученных данных авторы выяснили, что по методике BSMAS только 4,5\% подростков соответствуют «Проблемному уровню использования социальных сетей». Как сообщают авторы, данным подросткам свойственны: низкий интерес к реальному миру и отстраненность от проблем в реальной жизни, толерантность к повышению своей активности в социальной сети, использование социальных сетей более 30 часов в неделю, пониженный уровень самооценки и более высокий уровень симптомов депрессии, чем у других участников эксперимента. Резюмируя полученные данные, исследователи заявляют, что ключевым критерием «Проблемного использования социальных сетей» является привыкание, характеризующееся проявлением симптомов абстиненции касательно использования социальных сетей [7].

Стоит отметить, что короткие тесты, направленные на исследование поведения людей в компьютерном виртуальном пространстве, которые позволяют быстро опросить большое число респондентов, на данный момент очень популярны в зарубежном научном поле. Помимо обозначенной Бергенской шкалы зависимости от социальных сетей (BSMAS), также широко используются такие тесты и опросники, как Шкала зависимости от приложений для смартфонов - Smartphone Application-Based Addiction Scale (SABAS), которая содержит 6 вопросов; Краткая шкала оценки проблемного использования онлайн-видеоигр - Internet Gaming Disorder ScaleShort Form [IGDS-SF9], которая содержит 9 вопросов; Опросник Европейского проекта по коррекции кибербуллинга - The European Cyberbullying Intervention Project Questionnaire (ECIPQ), имеющий перевод на 5 европейских языков и содержащий 22 вопроса $[11 ; 14 ; 22]$.

Говоря об изучении активности подростков в социальных сетях в рамках психологической науки, нужно также обозначить наличие факторов положительного влияния социальных сетей. Британские авторы К.М. Кеннеди, И. Бьюкен, Дж. Пауэлл и др. провели анализ 42 статей на тему положительной роли социальных сетей в укреплении психологического и физического здоровья пользователей. В результате проделанной работы авторы выяснили, что в социальных сетях присутствуют группы, оказывающие психологическую поддержку людям, страдающим алкогольной зависимостью и тягой к курению. Также некоторые исследования показывают наличие положительного влияния групп в социальных сетях, занимающихся социальной, психологической и правовой поддержкой людей, страдающих ожирением и диабетом, профилактикой ВИЧ-инфекции, борьбой с домашним и школьным насилием [6, с. 141]. 
Отметим, что подобные группы существуют и в отечественных социальных сетях (ВКонтакте и Одноклассники), они дают возможность конфиденциально обратиться в правозащитные организации, получить консультацию дипломированных специалистов различного профиля. Их создателями часто являются государственные клиники, правоохранительные органы и специализированные фонды.

Другим фактором положительного влияния социальных сетей на подростков и молодых людей может являться коммуникативная составляющая. Многие подростки испытывают проблемы, связанные с общением в реальном мире, что может быть обусловлено личностными особенностями или недостатком опыта общения. Социальная сеть исключает зрительный контакт, общение в ней может проходить в обезличенной форме. Подобные условия дают дополнительные возможности застенчивым подросткам и подросткам с ограниченными возможностями здоровья завести знакомства и получить социальную поддержку $[30 ; 35 ; 36 ; 39]$.

Коллектив исследователей из Швеции А. Эгдам, У. Хамиди, А. Бартфай, С. Кох изучил, каким образом социальная сеть Facebook может помочь людям с умеренными приобретенными когнитивными нарушениями получить социальную поддержку. Авторы в течение года наблюдали за процессом взаимодействия людей в специальной группе Facebook, участники которой имели подтвержденный диагноз приобретенной минимальной мозговой дисфункции, численность группы составила 1310 человек. Оценивались такие показатели, как публичные сообщения в группе, письменные комментарии к сообщениям и «лайки» к сообщениям. Классифицируя сделанные пользователями в течение года сообщения, исследователи показывают, что большинство постов $(57 \%)$ и комментариев (62\%) могут быть отнесены к разным видам социальной поддержки. Интересно, что только 17\% сообщений были направлены на желание получить поддержку, в то время как $40 \%$ сообщений были направлены на оказание социально-психологической поддержки другим. Чаще всего в рамках оказания взаимной поддержки участники группы делились информацией о своем состоянии и о том, как его преодолеть, подобное взаимодействие помогало людям бороться с одиночеством и отчаянием. Также популярными были такие виды общения, как добродушное подшучивание и обсуждение повседневной жизни [15].

Из представленных авторами аналитических графиков и диаграмм становится понятно, что некоторые пользователи чаще всего общались с одними и теме же людьми, что позволяет предположить возникновение 
более качественных, дружеских связей между ними. Полученные данные авторы сравнили с результатами аналогичных исследований тематически схожих публичных форумов и групп в Facebook и не выявили значимых различий. Учитывая полученные результаты, исследователи сообщают, что социальные сети (в данном случае Facebook) могут быть инструментом, помогающим лучше понять людей с особыми клиническими состояниями [15].

\section{Выводы}

В результате анализа зарубежных исследований, посвященных теме психологических особенностей использования социальных сетей подростками, был выявлен ряд направлений, находящихся в фокусе внимания зарубежного научного сообщества: проблема травли и издевательств, направленных на разрушение социального статуса в среде подростков при помощи социальных сетей; изучение проблемы соотношения частого использования социальных сетей и наличия у подростков психических расстройств; проблема распространения психоактивных веществ среди подростков при помощи сайтов социальных сетей; роль социальных сетей в провоцировании нанесения себе вреда подростками.

Помимо негативных последствий использования социальных сетей описаны исследования, показывающие примеры позитивного их воздействия на пользователей. В частности, сообщается о наличии специализированных групп в социальных сетях, занимающихся профилактикой таких проблем: распространение ВИЧ, диабета и ожирения; употребление ПАВ; домашнее и школьное насилие. Социальные сети также могут помогать людям, имеющим различные психологические расстройства. При помощи таких групп в социальных сетях, где все участники объединены одной проблемой, люди могут получать социальную поддержку, заводить и развивать знакомства.

Анализ особенностей использования социальных сетей подростками и молодыми людьми за рубежом может иметь теоретическую значимость для читателя, т.к. позволяет оценить опасности и преимущества, которые могут ожидать российское общество в связи с неизбежным процессом цифровизации почти всех социальных институтов в нашей стране.

Практическая значимость публикации заключается в освещении некоторых зарубежных инструментов диагностики влияния социальных 
сетей на человека, в частности приведен обзор «Бергенской шкалы зависимости от социальных сетей» (BSMAS), в рамках которого даны перевод бланка и ключа теста на русский язык.

В некоторых рассмотренных работах декларируется важный, на наш взгляд, вывод о том, что подростки, имеющие различные социальные и/ или психологические проблемы первичного характера, такие как депрессивное и тревожное расстройства, больше склонны к постоянному, бесконтрольному использованию социальных сетей. Дальнейшее развитие идеи вторичности проблемного использования социальных сетей и видеоигр по отношению к имеющимся у подростка дизадаптивным психосоциальным особенностям является крайне важным условием для понимания всех аспектов взаимодействия подростка с миром социальных сетей и видеоигр.

\section{Библиографический список / References}

1. Российский центр изучения общественного мнения (ВЦИОМ). 03.06.2019. Пресс-релиз № 3898. Подросток в соцсети: норма жизни - или сигнал об опасности? URL: https://wciom.ru/index.php?id=236\&uid=9587 (дата обращения: 20.06.2019).

2. Alavi N., Reshetukha T., Prost E., Antoniak K. et al. Relationship between bullying and suicidal behaviour in youth presenting to the emergency department. Journal of the Canadian Academy of Child and Adolescent Psychiatry. 2017. Vol. 26. Iss. 2. Pp. 70-77.

3. Andreassen C.S., Billieux J., Griffiths M.D. et al. The relationship between addictive use of social media and video games and symptoms of psychiatric disorders: A large-scale cross-sectional study. Psychology of Addictive Behaviors. 2016. Vol. 30. Iss. 2. Pp. 252-262. URL: http://dx.doi.org/10.1037/ adb0000160

4. Andreassen C.S., Torsheim T., Brunborg G.S., Pallesen S. Development of a Facebook addiction scale. Psychological Reports. 2012. Vol. 110. Iss. 2. Pp. 501-517. DOI: 10.2466/02.09.18.PR0.110.2.501-517.

5. Atroszko P.A., Balcerowska J.M., Bereznowski P. et al. Facebook addiction among Polish undergraduate students: Validity of measurement and relationship with personality and well-being. Comput Hum Behav. 2018. Vol. 85. Pp. 329-338. DOI: 10.1016/j.chb.2018.04.001

6. Balatsoukas P., Kennedy C.M., Buchan I. et al. The role of social network technologies in online health promotion: A narrative review of theoretical and empirical factors influencing intervention effectiveness. Journal of Medical Internet Research. 2015. Vol. 17. Iss. 6. P. 141. DOI: 10.2196/jmir.3662.

7. Bányai F., Zsila Á., Király O. et al. Problematic social media use: Results from a large-scale nationally representative adolescent sample. PLOS ONE. 2017. Vol. 12. Iss. 1. URL: https://doi.org/10.1371/journal.pone.0169839 
8. Barman L., Mukhopadhyay D.K., Bandyopadhyay G.K. Use of social networking site and mental disorders among medical students in Kolkata. Indian J. Psychiatry. 2018. Vol. 60. Iss. 3. Pp. 340-345. DOI: 10.4103/psychiatry. IndianJPsychiatry_210_18.

9. Bergmann M.C., Baier D. Prevalence and correlates of cyberbullying perpetration. Findings from a German representative student survey. Int. J. Environ Res Public. 2018. Vol. 15. Iss. 7. P. 274. DOI: 10.3390/ijerph15020274.

10. Biddle L., Derges J., Goldsmith C. et al. Using the internet for suicide-related purposes: Contrasting findings from young people in the community and selfharm patients admitted to hospital. PLoS ONE. 2018. Vol. 13. Iss. 5. DOI: 10.1371/journal.pone.0197712.

11. Brighi A., Menin D., Skrzypiec G., Guarini A. Young, bullying, and connected. Common pathways to cyberbullying and problematic internet use in adolescence. Frontiers in Psychology. 2019. Vol. 10. P. 1467. DOI: 10.3389/ fpsyg.2019.01467.

12. Brunborg G.S., Andreas J.B. Increase in time spent on social media is associated with modest increase in depression, conduct problems, and episodic heavy drinking. Journal of Adolescence. 2019. Vol. 74. Pp. 201-209. DOI: 10.1016/j. adolescence.2019.06.013.

13. Cunningham C.E., Chen Y., Vaillancourt T. et al. Modeling the anticyberbullying preferences of university students: Adaptive choice-based conjoint analysis. Aggress. Behav. 2015. Vol. 44. Iss. 4. Pp. 369-385. DOI: 10.1002/ab.21560.

14. Del R.R., Ortega-Ruiz R., Casas J.A. Asegúrate: An Intervention Program against cyberbullying based on teachers' commitment and on design of its instructional materials. Int. J. Environ Res Public Health. 2019. Vol. 16. Iss. 3. P. 434. DOI: 10.3390/ijerph16030434.

15. Eghdam A., Hamidi U., Bartfai A., Koch S. Facebook as communication support for persons with potential mild acquired cognitive impairment: A content and social network analysis study. PLoS One. 2018. Vol. 13. Iss. 1. URL: https://doi. org/10.1371/journal.pone.0191878

16. Evans-Brown M., Sedefov R. Responding to new psychoactive substances in the European Union: Early warning, risk assessment, and control measures. New Psychoactive Substances. Chapter from Handbook of Experimental Pharmacology. H. Maurer, S. Brandt (eds.) 2018. Vol. 252. Pp. 3-49. DOI: 10.1007/164_2018_160.

17. Finne J., Roland E., Svartdal F. Relational rehabilitation: Reducing the harmful effects of bullying. Nordic Studies in Education. 2018. Vol. 38. Pp. 352-367. DOI: https://doi.org/10.18261/issn.1891-2018-04-05

18. Guarini A., Menin D., Menabò L., Brighi A. RPC Teacher-Based Program for improving coping strategies to deal with cyberbullying. Int. J. Environ Res Public Health. 2019. Vol. 16. Iss. 6. P. 948. DOI: 10.3390/ijerph16060948.

19. Hussain Z., Griffiths M.D. Problematic social networking site use and comorbid psychiatric disorders: A systematic review of recent large-scale studies. Frontiers in Psychology. 2018. Vol. 9. P. 686. 
20. John A., Glendenning A.C., Marchant A. et al. Self-harm, suicidal behaviours, and cyberbullying in children and young people: Systematic review. Journal of Medical Internet Research. 2018. Vol. 20. Iss. 4. P. 129. DOI: 10.2196/ jmir.9044.

21. Kim S.J., Marsch L.A., Hancock J.T. et al. Scaling up research on drug abuse and addiction through social media big data. Journal of medical Internet research. 2017. Vol. 19. Iss. 10. DOI: 10.2196/jmir.642.

22. Leung H., Pakpour A.H., Strong C. et al. Measurement invariance across young adults from Hong Kong and Taiwan among three internet-related addiction scales: Bergen Social Media Addiction Scale (BSMAS), Smartphone Application-Based Addiction Scale (SABAS), and Internet Gaming Disorder Scale-Short Form (IGDS-SF9) (Study Part A). Addictive Behaviors. 2019. 04. URL: https://doi.org/10.1016/j.addbeh.2019.04.027

23. Li J.B., Mo P.K.H., Lau J.T.F. et al. Online social networking addiction and depression: The results from a large-scale prospective cohort study in Chinese adolescents. Journal of Behavioral Addictions. 2018. Vol. 7. Iss. 3. Pp. 686-696. DOI: 10.1556/2006.7.2018.69. URL: https://akademiai.com/ doi/10.1556/2006.7.2018.69

24. Machimbarrena J.M. et al. Internet risks: An overview of victimization in cyberbullying, cyber dating abuse, sexting, online grooming and problematic Internet use. International Journal of Environmental Research and Public Health. 2018. Vol. 15. Iss. 11. DOI: 10.3390/ijerph15112471.

25. Martínez-Ferrer B., Moreno D., Musitu G. Are adolescents engaged in the problematic use of social networking sites more involved in peer aggression and victimization? Frontiers in Psychology. 2018. Vol. 9. P. 801. URL: https://doi.org/10.3389/fpsyg.2018.00801

26. Memon A.M., Sharma S.G., Mohite S.S., Jain S. The role of online social networking on deliberate self-harm and suicidality in adolescents: A systematized review of literature. Indian Journal of Psychiatry. 2018. Vol. 60. Iss. 4. Pp. 384-392. DOI: 10.4103/psychiatry.IndianJPsychiatry_414_17.

27. Miliano C., Margiani G., Fattore L., De Luca M.A. Sales and advertising channels of New Psychoactive Substances (NPS): Internet, Social Networks, and Smartphone Apps. Brain Sciences. 2018. Vol. 8. Iss. 7. Pp. 152-160. DOI: 10.3390/brainsci8070123.

28. Moyle L., Childs A., Coomber R., Barratt M.J. Drugsforsale: An exploration of the use of social media and encrypted messaging apps to supply and access drugs. International Journal of Drug Policy. 2019. Vol. 63. Pp. 101-110. DOI: 10.1016/j.drugpo.2018.08.005.

29. Myers C.A., Cowie H. Cyberbullying across the lifespan of education: Issues and Interventions from School to University. Int. J. Environ Res Public Health. 2019. Vol. 16. Iss. 7. DOI: 10.3390/ijerph16071217.

30. Nesi J., Choukas-Bradley S., Prinstein M.J. Transformation of adolescent peer relations in the social media context. Part 1: Theoretical framework and application to dyadic peer relationships. Clinical Child and Family Psychology Review. 2018. Vol. 21. Iss. 3. Pp. 267-294. DOI: 10.1007/s10567-018-0261-x. 
31. Nesi J., Choukas-Bradley S., Prinstein M.J. Transformation of adolescent peer relations in the social media context: Part 2: Application to peer group processes and future directions for research. Clinical Child and Family Psychology Review. 2018. Vol. 21. Iss. 3. Pp. 295-319. DOI: 10.1007/s10567-0180262-9.

32. Peng Z., Klomek A.B., Li L. et al. Associations between Chinese adolescents subjected to traditional and cyber bullying and suicidal ideation, self-harm and suicide attempts. BMC Psychiatry. 2019. Vol. 19, Iss. 1. P. 324. DOI: 10.1186/ s12888-019-2319-9.

33. Pontes H.M. Investigating the differential effects of social networking site addiction and Internet gaming disorder on psychological health. J. Behav Addict. 2017. Vol. 6. Iss. 4. Pp. 601-610. DOI: 10.1556/2006.6.2017.075

34. Romer D., Moreno M. Digital media and risks for adolescent substance abuse and problematic gambling. Pediatrics. 2017. Vol. 140. Iss. 2. DOI: 10.1542/ peds.2016-1758L.

35. Schalkwyk G.I., Marin C.E., Ortiz M. et al. Social media use, friendship quality, and the moderating role of anxiety in adolescents with autism spectrum disorder. Journal of Autism and Developmental Disorders. 2017. Vol. 47. Iss. 9. Pp. 2805-2813. DOI: 10.1007/s10803-017-3201-6.

36. Seabrook E.M., Kern M.L., Rickard N.S. Social networking sites, depression, and anxiety: A systematic review. JMIR Mental Health. 2016. Vol. 3. Iss. 4. DOI: 10.2196/mental.5842.

37. Sjursø I.R., Fandrem H., Norman J.O., Roland E. Teacher authority in longlasting cases of bullying: a qualitative study from Norway and Ireland. J. Environ Res Public Health. 2019. Vol. 16. Iss. 7. DOI: 10.3390/ijerph16071163.

38. Sorrentino A., Baldry A.C., Farrington D.P. The efficacy of the tabby improved prevention and intervention program in reducing cyberbullying and cybervictimization among students. Int. J. Environ Res Public Health. 2018. Vol. 15. Iss. 11. DOI: 10.3390/ijerph15112536.

39. Underwood M.K., Ehrenreich S.E. The power and the pain of adolescents' digital communication: Cyber victimization and the perils of lurking. The American Psychologist. 2017. Vol. 72. Iss. 2. Pp. 144-158. DOI: 10.1037/a0040429.

40. Van Hee C., Jacobs G., Emmery C. et al. Automatic detection of cyberbullying in social media text. PLoS One. 2018. Vol. 13. Iss. 10. DOI: 10.1371/journal. pone.0203794.

41. Wadsworth E., Drummond C., Kimergard A., Deluca P. A market on both "sides" of the law: The use of the hidden web for the sale of new psychoactive substances. Hum Psychopharmacol. 2017. Vol. 32. Iss. 3. Pp. 101-110. DOI: 10.1002/hup. 2596 .

Статья поступила в редакцию 16.01.2020, принята к публикации 11.03.2020

The article was received on 16.01.2020, accepted for publication 11.03.2020 
Сведения об авторе / About the author

Шубин Сергей Борисович - педагог-психолог, Школа № 460 имени дважды Героев Советского Союза А.А. Головачёва и С.Ф. Шутова, г. Москва

Sergey B. Shubin - educational psychologist, State Budgetary Educational Institution "School No. 460", Moscow

E-mail: sergej_shubin_93@mail.ru 